\title{
Perceiving minimal distinctions in ASL under normal and point-light display conditions
}

\author{
VIVIEN C. TARTTER \\ Rutgers University, Camden, New Jersey, and Bell Laboratories, Murray Hill, New Jersey \\ and \\ SUSAN D. FISCHER \\ National Technical Institute for the Deaf, Rochester, New York
}

\begin{abstract}
Perceptual confusions within 36 formationally minimal pairs of signs were assessed for native signers under two conditions of video presentation: (1) normally lighted black-and-white displays and (2) point-light displays constructed by affixing 26 points of retroreflective tape on the fingertips, back knuckles, and wrists and 1 point on the nose of the signer. Nine pairs were selected for each of the formational parameters of handshape, location, movement, and orientation. For each minimal pair, a native signer constructed and signed an ASL sentence that was syntactically and semantically appropriate for both members of the pair. Fourteen highly fluent ASL users responded by selecting a picture appropriate to the viewed sentence, thus avoiding contamination by English. For both viewing conditions, subjects discriminated the minimal pairs significantly better than chance. Performance was better (1) when location or orientation differentiated the signs than when movement or handshape did and (2) in normal light. ing than in the point-light displays. With the point-light displays, discrimination of location, movement, and orientation was poorer and handshape discrimination was at chance. The discussion considers (1) the confusion of signs in the absence of linguistic redundancy, (2) the effectiveness of the point-light configurations as "minimal cues" for the contrasts, and (3) the efficacy of using these point-light configurations to reduce the information in ASL to a narrow bandwidth.
\end{abstract}

American Sign Language (ASL) is the sign language used by members of the deaf community of the United States. It is produced primarily by rule-governed movements of the hand or hands, articulated between the top of the head and the waist and within $1 \mathrm{ft}$ of either side of the torso. ASL is linguistically distinct from other sign languages but appears to share with them similar structural characteristics, much as the spoken languages of the world share articulatory features.

Signs used in ASL have been described as a combination of the four formational parameters of handshape, movement, location in the signing space (Stokoe, Casterline, \& Croneburg, 1965), and hand orientation (Battison, 1974, 1978). For example, the sign THINK

We are grateful to Keith Cagle for his invaluable assistance in construction and production of the stimuli and in administering the experiment. We also thank David Banks and Kathy Monsu for their help in scoring the data, Andrew Rothman for the artistic renditions of the sentences, and Osamu Fujimura for his support and suggestions throughout the project. We would also like to thank Martha Teghtsoonian for her valuable assistance in revising the manuscript. This research was partially funded by Bell Laboratories. Fischer's research is supported under an agreement between the Department of Education and NTID (National Technical Institute for the Deaf at Rochester Institute of Technology). Correspondence should be addressed to Vivien C. Tartter, Psychology Department, Rutgers University, Camden, New Jersey 08102. is produced with the index finger pointing upward and toward the head, the back of the hand forward, and the hand positioned roughly at the temple. It contrasts in handshape with the sign KNOW, in which all the fingers are extended, in movement with THINK-ABOUT, in which the index finger traces circles at the point of articulation on the forehead, in location with ME, in which the index finger points to the center of the chest, and in orientation with one sign for GERMANY, in which the palm of the hand faces outward. Most signs, of course, contrast along several of these dimensions, rather than just one.

In a recent study, Tartter and Knowlton (1981) demonstrated that conversation in ASL could be comprehended when the only visible points were retroreflective markers on each fingertip $(n=10)$ and back knuckle $(n=8)$ of a pair of gloves, four small circles around each wrist of each glove, and one large circle on the nose of the signer. Tartter and Knowlton assumed that the ease with which subjects communicated depended on the efficacy of the dot configurations in conveying information about the formational parameters. However, the communication task given to the subjects was to converse, and conversation is redundant on many levels: It is structured with respect to topic, social rules, semantics, and grammar, as well as "phonology," and thus guesses at large segments may frequently be correct. Hence, it is possible that the conversants suffered from 
a loss of information at the "phonological" level, but without observable effect on the conversations.

The primary purpose of the current study was to assess precisely what low-level information signers have available from signs and to what extent that information is preserved in these dot displays. Signers performed a forced-choice identification of pairs of natural signs contrasting in values of only one formational parameter (e.g., THINK vs. KNOW, contrasting in handshape only). Discriminability of normal videotaped pairs was compared with discriminability of the same pairs filmed using the point-light displays.

A second important purpose of the present study was to provide baseline data on the relative confusability of minimally contrasting signs, roughly analogous to the data provided by Miller and Nicely (1955) on the perceptibility of minimal articulatory contrasts in speech.

It should be noted that the formational characteristics of sign have been demonstrated to have a psychological reality in production, memory, and comprehension of sign, and they are assumed to have psychological reality in perception. Bellugi and Siple (1974; also Klima \& Bellugi, 1979) found that intrusion errors in short-term memory generally preserved all but one of the four values. Further, as compared with lists in which all parameters were different, lists in which one of the parameters was constant were recalled best when handshape was shared among the list items and worst when location was shared. Studies of spontaneous slips of the hand (Klima \& Bellugi, 1979) also suggest the independence of the formational parameters, as do errors in imitation of signs electronically aborted at various stages of production (Grosjean, 1981).

Previous research directed at perception of sign has generally been concerned with discriminability within one formational parameter (Hawes \& Danhauer, 1978; Lane, Boyes-Braem, \& Bellugi, 1976; Poizner, Bellugi, \& Lutes-Driscoll, 1981; Poizner \& Lane, 1978; Stungis, 1981; Bellman, Poizner, \& Bellugi, Note 1). Across studies, different types of interference have been used, and these may differentially affect the distortion of the sign parameters, in the same manner as the type of distortion affects the relative salience of the articulatory features for speech (see, for example, the reanalysis of the data of Miller \& Nicely, 1955, performed by Wish \& Carroll, 1974). And in all of the studies cited, the sign was not judged in a natural language context but was presented in isolation. Since these factors can considerably affect perceptual strategies, the results may not reflect the strategies used in natural processing. The present study is designed in part to correct for these difficulties, by collecting judgments of discriminability of all four parameters under the same distortion conditions in a natural sentence context. This permits an assessment of which particular discriminations are difficult, whether distinctions cued by one parameter are more difficult than those cued by another, and, finally, whether the distortion produced by the light displays has a uniform effect on sign discriminability.

\section{METHOD}

\section{Stimulus Preparation}

Consultant. A native signer, who is a trained ASL informant, assisted us in selecting the stimuli and composing ASL sentences; this ensured that the stimuli were appropriate to ASL. He also produced the sentences for the videotape and helped compose and deliver instructions. He is one of three deaf siblings with deaf parents and grandparents and was a junior at the National Technical Institute for the Deaf. He was paid for his assistance.

Stimuli. Table 1 shows the 36 pairs of signs, 9 for each formational parameter, selected so that members of each pair differed only in the value for one parameter. For each pair, an ASL sentence in which either sign was syntactically and semantically appropriate was constructed; the 36 sentence frames are shown in the Appendix. A cartoon was drawn to capture the meaning of each sentence and make clear the distinction between the members of the minimal pair; Figure 1 shows sample contrasting sentences and associated drawings. It is interesting that very few minimal contrasts could occur in the same syntactic frame and could also be conveyed by picture; this suggests that the language compensates for potential "phonetic" confusion by increasing syntactic and semantic redundancy. The relative scarcity of minimal pairs produced a serious constraint on stimulus selection: For movement and location, all the pairs located by dictionary (Stokoe et al., 1965) were used, and these did not necessarily include all feature values. For handshape and orientation, more pairs existed and pairs were selected to be representative of the subparameter feature values.

Videotapes. The sentences were signed by the consultant under normal lighting conditions and then again under the conditions described by Tartter and Knowlton (1981). For the latter, the signer wore gloves to which were attached small blobs of retroreflective tape. There were 13 on each glove: 5 placed on the fingertips, 4 on the backs of the second joints on the fingers, and 4 around the wrist. In addition, one large spot of tape was placed on the signer's nose. Following the procedure described by Johannson (1973) and Kozlowski and Cutting (1977), a light was mounted next to the TV camera that directly illuminated the signer, causing the blobs to appear as bright dots on the videotape. Appropriate adjustment of brightness and contrast on the playback monitor rendered visible only the retroreflective tape. Figure 2 shows the back of a glove under both normal and the special lighting (DOTS) condition.

A test tape was produced for the normal and DOTS conditions. Each tape contained 72 sentences: The first 36 contained one member of each pair, randomized (A); the second 36 contained the other members of the pairs in a different random order (B). A practice tape, using two sentence pairs, satisfying the same conditions but not part of the test tape, was also produced.

The filming was done using a black-and-white TV camera (Panasonic WV 1100) fitted with a Polaris $20-$ to $80-\mathrm{mm}$ zoom lens. The signer sat approximately $4 \mathrm{ft}$ from the camera. The sentences were recorded on a SONY 2850.75 -in. videocassette recorder, and the final tapes were produced using two SONY 2860 videocassette machines and a SONY RM-430 automatic editing control unit. Videotape playback was from a SONY VO2600 videocassette recorder to two Sharp XR-195R monitors. For the DOTS condition, the brightness and contrast were calibrated on the two monitors.

\section{Subjects}

Fourteen adults (students and staff) associated with the National Technical Institute for the Deaf served as subjects. All were congenitally and profoundly deaf and had started learning ASL before 5 years of age. They were paid for their participation.

\section{Procedure}

The subjects were tested in two groups of eight subjects and six subjects, respectively. Group 1 received tapes in the order 
Table 1

Articulatory Distinctions and Performance Between Members of Each Pair for Four Formational Parameters

\begin{tabular}{|c|c|c|c|}
\hline \multirow[b]{2}{*}{ Pair } & \multirow[b]{2}{*}{ Constant } & \multicolumn{2}{|c|}{ Percent Correct Choices } \\
\hline & & Normal & Dots \\
\hline \multicolumn{4}{|c|}{ Location } \\
\hline VOLUNTEER/CURIOUS & Chest/Neck & $14-12 *$ & $9-14^{*}$ \\
\hline PRINT/BIRD & Base hand/Chin & $13-14^{*}$ & $13-14 *$ \\
\hline APPLE/KEY & Mouth side/Base hand & $10-13^{*}$ & $8-13$ \\
\hline FORGET/BETTER & Forehead/Chin & $14-12 *$ & $9-12$ \\
\hline BUGS/DEVIL & Nose/Temple & $10-13^{*}$ & $11 \cdot 9$ \\
\hline BORING/UGLY & Under mouth/Under nose & $11-13^{*}$ & $9-6$ \\
\hline TOOTHACHE/HEADACHE & Mouth side/Forehead & $14-12 *$ & $13-13^{*}$ \\
\hline GUILTY/ALARM & Chest/Base hand & $11-12 *$ & $11-12 *$ \\
\hline BOOK/OPEN-DOOR & Out in space/Base hand & $14-14^{*}$ & $14-14 *$ \\
\hline \multicolumn{4}{|c|}{ Orientation } \\
\hline SOCKS/STARS & Palms down/Palms out, fingers up & $13-13^{*}$ & $11-11^{*}$ \\
\hline WANT/FREEZE & Palm up/Palm down & $12-14^{*}$ & $12-13^{*}$ \\
\hline WORK/ROCKS & Palm out/Palm down & 13. $9 *$ & $12-3$ \\
\hline EACH OTHER/SCIENCE & Hands above each other/Hands parallel & $12 \cdot 10^{*}$ & $12-11 *$ \\
\hline BEAR/MONKEY & Hands crossed/Hands uncrossed & $14-14^{*}$ & $14-13^{*}$ \\
\hline WALK/SERVE & Palm down/Palm up & $13-14^{*}$ & $13-13^{*}$ \\
\hline ARGUMENT/ALARM & Palm toward body/Palm away from body & $14-13^{*}$ & $9-10$ \\
\hline BLUE/MIRROR & Arm down/Arm up & $14-12^{*}$ & $11-11 *$ \\
\hline FISH/FLAG & Arm down/Arm up & 7- 0 & $12 \cdot 0$ \\
\hline \multicolumn{4}{|c|}{ Movement } \\
\hline TYPEWRITER/PIANO & Alternating up and down/Finger wiggling side to side & $13-14^{*}$ & $9-14^{*}$ \\
\hline PATIENT/SUFFER & Downward/Repeated wrist twist & $5-3$ & $5-11$ \\
\hline DRIVING/CARS & Hands synchronous/Hands alternating & $14-11 *$ & $8-12$ \\
\hline JOIN/QUIT & Movement toward base hand/Movement away from base hand & $14-11 *$ & $10-7$ \\
\hline SCHOOLS/PAPER & Slapping/Brushing & $12-14^{*}$ & $5-14$ \\
\hline THREAD/SPAGHETTI $†$ & Hands move apart/Hands move together & $6-13$ & $0-12$ \\
\hline PLUG-IN/APPLY† & Straight/Arc & 2- 7 & 13- 6 \\
\hline SOAP/PAINT + & Repeated one-direction movement/Back-and-forth movement & 14- 9 & $11-9$ \\
\hline DEMAND/DIG $\dagger$ & Signing hand moves with base hand/Signing hand moves on base hand & $3-14$ & 3-11 \\
\hline \multicolumn{4}{|c|}{ Handshape } \\
\hline IRISH/PRINCIPAL & Bent fingers/Straight fingers and thumb contact & 8- 8 & 8- 8 \\
\hline APPROVE/STOP & Closed hand/Open hand & $9-10$ & $7-7$ \\
\hline WATER/VINEGAR & Three fingers extended/Two fingers extended & $9-11$ & 8- 8 \\
\hline RAIN/DYE & Bent fingers/Extended fingers and thumb contact & $13-13^{*}$ & $12-3$ \\
\hline FINISH/DON'T WANT & Straight fingers/Bent fingers & $14-14^{*}$ & $6-10$ \\
\hline AGREE/BET & One finger extended/Four fingers extended & $6-4$ & 3- 4 \\
\hline DANCE/PAINT & Fingers spread/Fingers closed & $13-14^{*}$ & $0-12$ \\
\hline WORSHIP/WRESTLE & Bent fingers/Straight fingers & $14-11^{*}$ & $6-14$ \\
\hline TIME/POTATO ${ }^{+}$ & One finger/Two fingers & $3-13$ & $6-10$ \\
\hline
\end{tabular}

* Better than confidence interval for chance.

tShowed a significant difference (response bias) in the normal condition between the two signs.

Normal A, DOTS A, DOTS B, Normal B; Group 2 received tapes in the order DOTS B, Normal B, Normal A, DOTS A. Each group was tested in one 2 -h session, with a break between the first and second halves of the test. After each sentence, two slides labeled " 1 " and " 2 " were projected. Subjects indicated their responses by writing the appropriate number of the picture that best depicted the sentence.

Subjects were told that we were interested in how sign language was perceived and whether it could be transmitted by point-light displays, for possible development into a telephone. We emphasized that our interest was in comparing systems and not in individual performance. Subjects were told that at times the task would be very difficult and to guess when unsure, and that they would frequently see similar sentences and might see the same sentence twice. At the start of the session, the pointlight displays were described and practice trials for the DOTS condition were presented. Subjects viewed the practice with normal brightness and contrast to see where the DOTS were, and then with brightness and contrast adjusted so that only the DOTS appeared. They could view the practice trials again.

\section{RESULTS}

In each condition, each subject made one response per stimulus, which was scored "correct" or "incorrect." Two types of analyses were performed. First, analyses of the errors for the normal condition were undertaken to determine the perceptibility of the minimal articulatory contrasts and to provide a baseline for performance in our task. Second, performances in the DOTS and normal conditions were compared to measure the effects of DOTS distortion.

\section{Perceptibility of Normal Videotaped \\ Minimal Pairs}

One sign in any pair might be more frequent than the other (no norms exist for frequency of occurrence of 


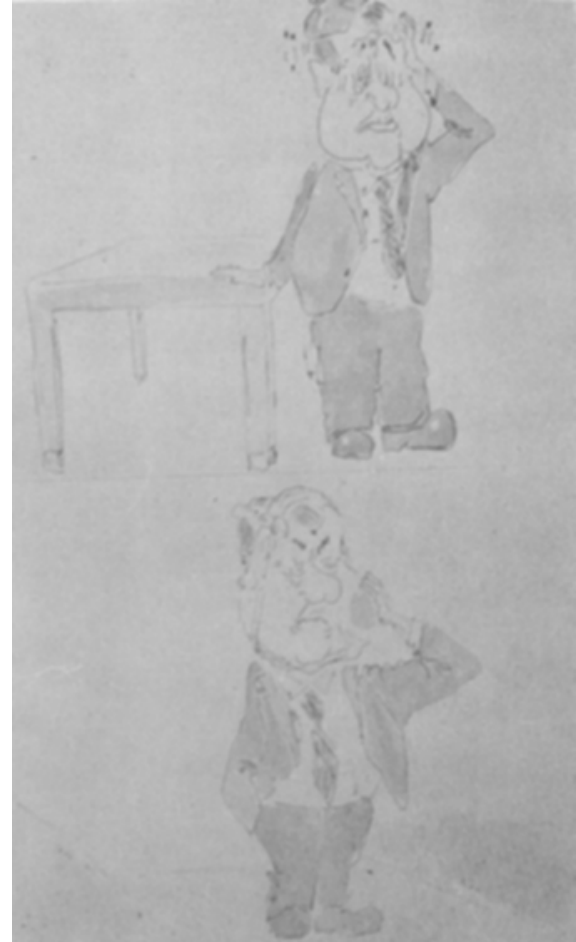

(a)

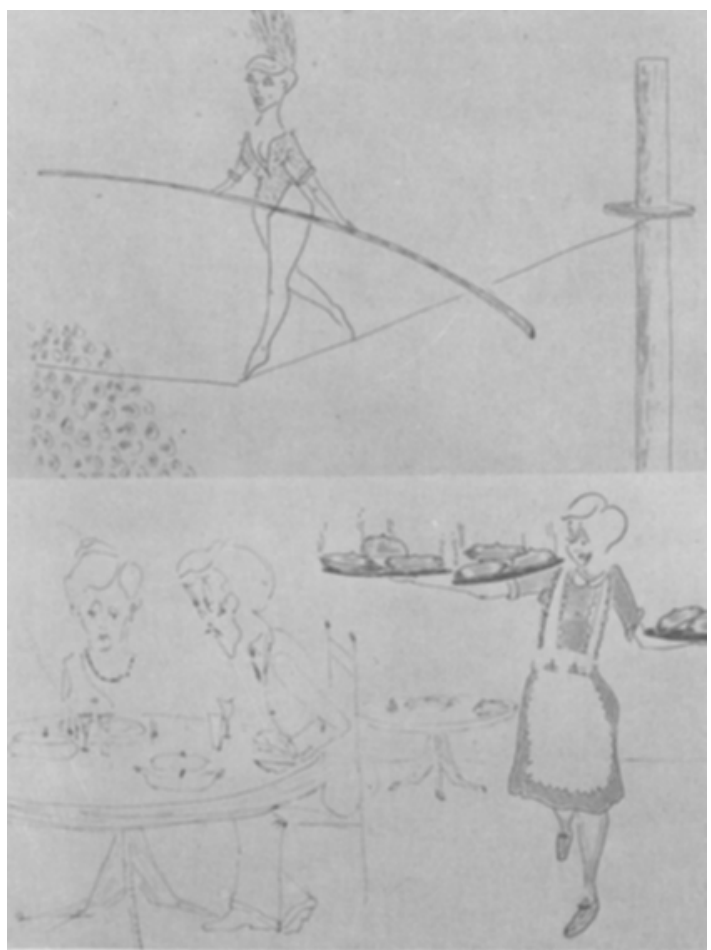

(c)

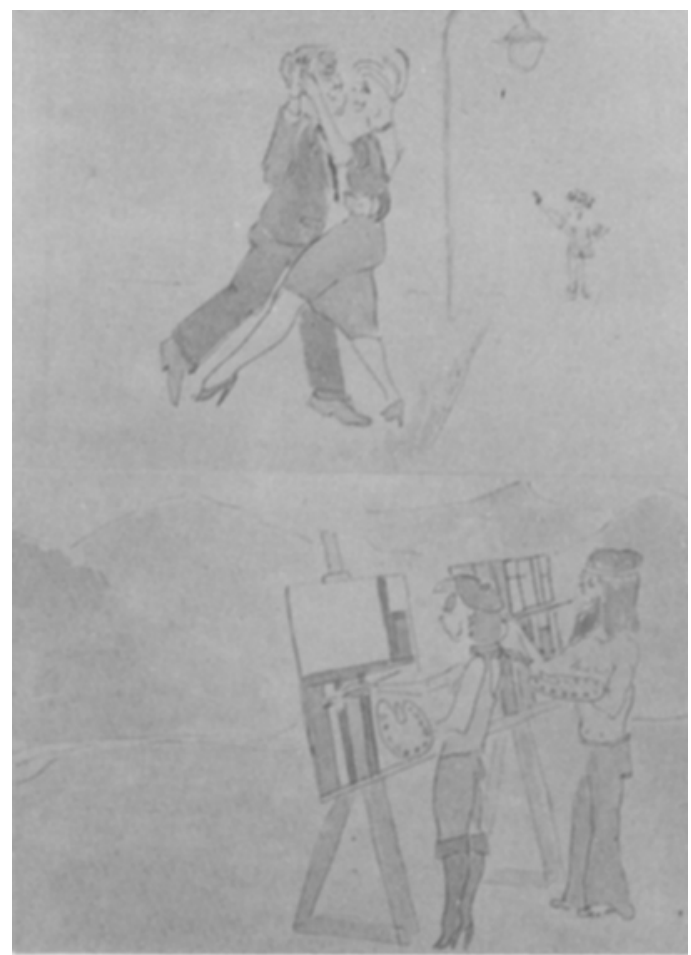

(b)

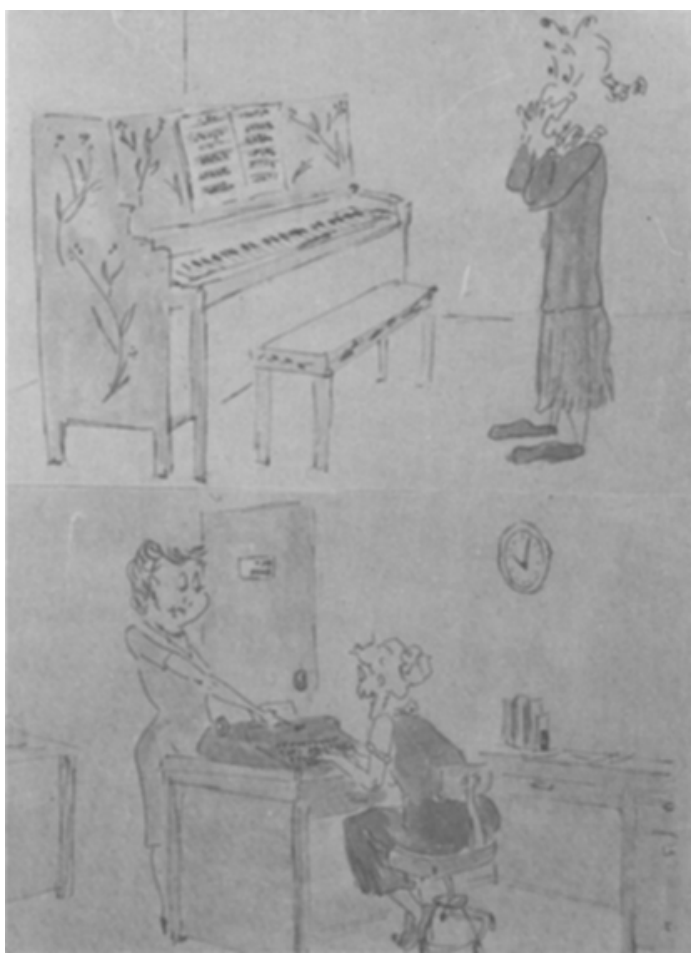

(d)

Figure 1. Cartoons exemplifying minimal contrasts of (a) location (He has a headache/toothache), (b) handshape (The two of them love to dance/paint together), (c) orientation (She serves/walks skillfully), and (d) movement (My grandmother loves the piano/ typewriter). 


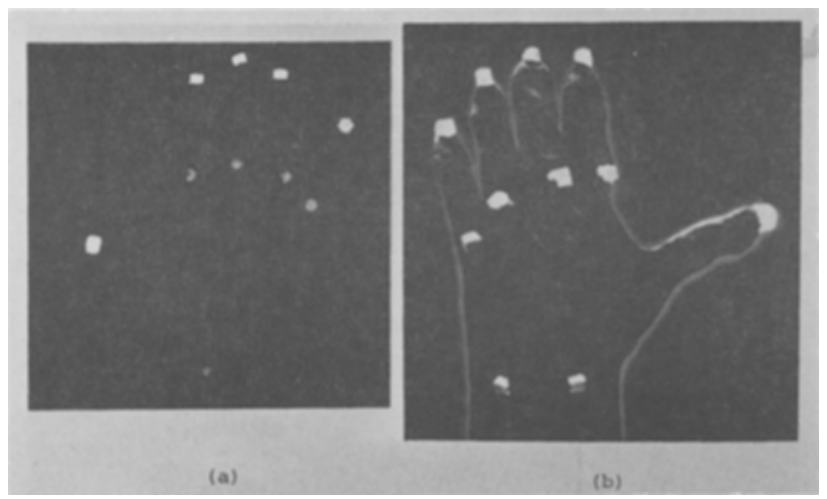

Figure 2. The back of a hand under (a) normal- and (b) point-light display conditions (after Tartter \& Knowlton, 1981 ).

items within ASL). Moreover, it is possible that either the sentence frame or the cartoons might be more suitable for one member of the pair than for the other. Thus, choice between items representing the same formational parameter may be affected by sign frequency, sentence appropriateness, and cartoon appropriateness, as well as discriminability. Analyses of the normal condition alone provide a control for these possible variations for this study, and they also provide normative data for future studies.

The difference in correct choices was calculated for members of each pair. (Perfect performance for a pair would be a score of 14 for each member, since there were 14 subjects.) For 30 of the 36 pairs, the different scores fell within the 95\% confidence interval (0-4) for same performance. The remaining 6 are footnoted in Table 1. ${ }^{1}$ Thus, for most of the pairs, there was no significant bias toward one member.

Although all pairs representing minimal contrasts in the same parameter are one feature apart, some values of that feature may be more discriminable than others; in speech, for example, [z]-[s] and [b]-[p] each contrasts minimally in voicing, but they may be differently discriminable. Indeed, Lane et al. (1976), Poizner and Lane (1978), and Bellman et al. (Note 1) have each shown hierarchical clustering patterns within one parameter.

Within-parameter differences for the present corpus were examined both quantitatively and qualitatively. The performance on the two members of the pair was averaged for each subject and summed across subjects. The mean, standard deviation, and range of performance across pairs are shown for each parameter in Table 2. It can be seen that the range and standard deviation of performance were about the same for the pairs representing orientation, movement, and handshape, with some pairs identified with lower than chance accuracy and some with near-perfect accuracy. The average performance for these parameters indicates a reasonable degree of accuracy for most pairs. Location pairs were discriminated consistently well.

The distinctions between the pairs for each parameter were next examined to try to account for the observed error pattern in terms of visibility. Subjects' scores were totaled for each member of each pair, and then the scores for the members were averaged. Using a z-approximation to the binomial distribution, we computed the $95 \%$ confidence range for chance performance for 14 subjects and noted the pairs that fell outside that range. (Note that response-bias effects were minimized by using performance for the pair rather than for each item.) In Table 1, the pairs marked with an asterisk are those that were discriminated better than chance. Under normal lighting, each of the distinctions representing location was perceived significantly better than chance, suggesting little difference in discriminability in pairs within the parameter (perhaps because of a ceiling effect). For orientation also, most of the pairs were perceived significantly better than chance, allowing little room for within-parameter differences in discriminability. The one exception was FISH-FLAG, which we already have shown to have indicated a response bias. In this pair, the distinction was not as marked in the signs themselves as in the classifiers used subsequently in the sentences. Indeed, several subjects remarked about the difficulty of this particular sentence pair. For movement, some pairs were more easily identified than others, but a pattern was not discernible from this small sample of movements, especially since nearly half of the pairs seemed to be subject to response bias. For handshape, the pairs that were not perceived at better than chance levels had as distinctive differentiation either the number of fingers extended or the contrast between bent and straight fingers. It should be noted that more errors than expected by chance were made for the pair AGREE-BET; we suspect that this may be

Table 2

Mean, Standard Deviation, and Range of Accuracy of the 14 Subjects Across the Nine Pairs Representing Each Formational Parameter

\begin{tabular}{lrrr}
\hline & Mean & SD & Range \\
\hline Location & 12.5 & 1.0 & $11.5-14.0$ \\
Orientation & 11.7 & 3.3 & $3.5-14.0$ \\
Movement & 9.9 & 3.6 & $4.0-13.5$ \\
Handshape & 10.4 & 3.1 & $5.0-14.0$ \\
\hline
\end{tabular}


because of difficulty depicting the semantic distinction in the pictures.

\section{Comparison of Normal and DOTS Results}

The principal purpose of the study was to measure the effects of DOTS distortion on perception, by comparing perception of the DOTS stimuli with their normal counterparts. This can be measured in terms of accuracy for each pair and accuracy for each parameter. Table 1 permits comparison of the pairs discriminated better than chance in the normal condition with those discriminated better than chance in DOTS, both marked by asterisks. It can be seen that there are far more pairs identified significantly above chance in normal than in DOTS lighting and that, for both lighting conditions, location and orientation differences were more accurately perceived than handshape and movement differences.

To compare accuracy in discriminating values for each parameter for each condition, a two-way withinsubjects (condition $X$ parameter $X$ subjects) analysis of variance was computed. Fisher's least significant difference statistic (Winer, 1971) was used to assess pairwise differences. For the analysis of variance, performance for the pairs with no evident response bias representing each parameter was averaged for each subject. ${ }^{2}$ The average scores across subjects are displayed in Figure 3. As Figure 3 suggests, performance was better for normal than for DOTS lighting $[F(1,13)=147.76, p<.01]$, and there were differences among parameters $[\mathrm{F}(3,39)$ $=28.68, p<.01]$. Post hoc analysis indicated no significant difference between location and orientation or between movement and handshape, but a significant difference between these two sets of parameters. Finally, there was a significant condition $X$ parameter interaction $[F(3,39)=6.79, p<.01]$, indicating that the distortion produced by the DOTS lighting did not affect all parameters equally. Examination of Figure 3 together with post hoc tests suggests that the DOTS lighting depressed performance significantly for all the parameters, but most for handshape. The difference in handshape performance in the two conditions was significantly greater

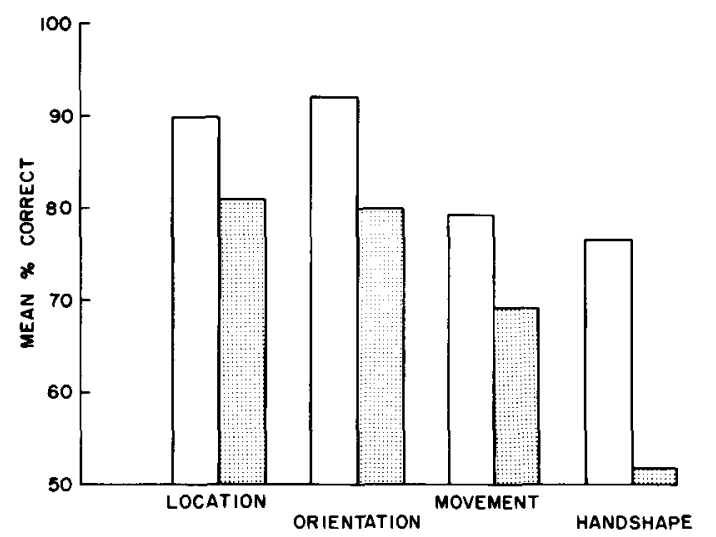

Figure 3. Average percent correct for each parameter under normal (blank) and DOTS (dots) lighting. than the difference for the other parameters $(p<.025)$; indeed, handshape discriminations in the DOTS condition were not significantly better than chance. [It is important to note that only one pair for movement was perceived at better than chance levels in DOTS, although performance across subjects was reliably better than chance. Very few signs are distinguished only by movement (we used all the pairs in the dictionary), and thus difficulties with movement here will probably not pose a problem for natural transmission.]

Examination of Table 1 also permits a qualitative assessment of the subparameter featural information passed by DOTS. Generally, if subjects did well on a pair in normal lighting, they did well on that pair in DOTS. The exceptions for handshape were RAIN-DYE and DANCE-PAINT; in each case, the visible cue in DOTS lighting was reduced to the distance of the dots from each other. For location, the pair BORING-UGLY was perceived much more poorly in DOTS lighting than in normal lighting, relative to the other pairs, and here the critical information in DOTS would be only the distance from the nose spot, the only facial feature marked. Two pairs representing movement were perceived better in DOTS than in normal lighting, perhaps because of accentuation of the critical cues, but more likely because of some carelessness in signing in the normal condition. The remaining pairs showed no particular pattern with respect to the effect of DOTS lighting. Finally, for orientation, the pairs WORK-ROCKS and ARGUMENT-ALARM were more affected by DOTS than were the other pairs. For the first, this could be because in ROCKS, the critical feature is the absence of the fingertips (they rest on the hand) and, as every mystery reader knows, it is difficult to detect the absence of something usually in a scene. We have no explanation for the greater confusion for ARGUMENT. ALARM.

\section{DISCUSSION}

There were several important purposes of this study: (1) to provide calibrations for the perceptibility of many of the naturally occurring minimal distinctions in sign language, (2) to specify precisely what subjects are able to see in DOTS lighting by examination of those distinctions that caused difficulty, and (3) to test the utility of the DOTS displays in conveying ASL.

With respect to the first purpose, it should be noted that there was variability in identification between items representing each parameter and that items that were more difficult sometimes shared subparameter features, suggesting that formational parameters are not perceptually indivisible. However, it is important to note also that there were significant effects of parameter in both normal and DOTS conditions. Moreover, the two conditions ordered the parameters similarly. This suggests, for these naturally occurring minimal contrasts, a decided reliable advantage for perceiving some types of distinctions over others. This has not been 
assessed previously, since no other study has examined the perception of each of the formational parameters simultaneously, under the same conditions and with the same subjects. We found that, for both conditions, location is slightly easier than orientation, which is much better than handshape, which in turn is better than movement (in the normal condition).

It is possible that the perceptual differences found are a result of the particular pairs selected rather than of perceptual differences inherent in the parameter. However, pairs were selected on the basis of those minimal distinctions in the language whose members could be differentiated by picture and could occur in the same sentence frame, not with regard to particular articulatory contrasts or semantic distinctiveness. Moreover, it is interesting to note that our perceptual findings are consistent with those of Bellugi and Siple (1974; Klima \& Bellugi, 1979) for memory, in which a greater number of minimally distinctive signs were used, and in which the signs were presented in isolation. They found that in short-term memory, recall was enhanced when all the items in a list shared the same handshape-If handshape is harder to perceive and remember than the other parameters, then being able to factor it out of a list will significantly reduce memory load. Location, on the other hand, which the memory study found to depress recall, may be most salient in distinguishing and recalling signs; therefore, using tests in which that differentiation is irrelevant will most greatly impede performance.

It is interesting to note that even under relatively normal conditions, perception of the minimal contrasts was not perfect, suggesting some interference with comprehension. Some of this interference is undoubtedly due to the task itself: Some of the pictures may not have been as clearly representative of the meaning of the sentence as we had intended. In addition, merely having a video image instead of the live person can lead to a loss of depth information; this is particularly true with a diffuse light source such as was used in the taping, which can lead to a flat-looking picture. Finally, although a sentence context is more natural than presentation of an isolated word, it is still less natural than a discourse context.

A principal purpose of this study was to assess what low-level information subjects use in perceiving DOTS displays. This can be done by examining those pairs discriminated better than chance in normal lighting but not in DOTS lighting. For location, three of four such pairs required discriminating locations on the face, an area relatively undifferentiated in DOTS, the only feature marked being the nose. For the two orientation pairs with differential accuracy in the two conditions, one result of the change in orientation is that for one member of each pair, the fingertips of the signing hand are not visible, requiring subjects to be aware of something that is not there. The awareness of absence is not necessary in the normal condition, since subjects have available information about the presence of the backs of the second finger joints. Differences in movement present insufficient data for us to discern a pattern of errors within the parameter either for the normal condition alone or for differences between normal and DOTS viewing. For three of the four handshape pairs with differential accuracy, a critical distinction is whether the fingertips are bent: In DOTS lighting, bending is cued only by a change in distance of the fingertips from some reference point; there is neither curvature nor wrinkling visible.

Although there are some differences in perception of DOTS and normal signs, perception of DOTS contains many features in common with normal video displays. We found that at least some minimal contrasts in movement, orientation, and location are discernible from the DOTS displays, to a slightly lower degree than from normal videotape displays, but that minimal contrasts in handshape are not discriminable at better than chance levels, at least for unpracticed subjects. The difficulty with handshape may not be so great a problem, since there are two indications that handshape can be easily guessed in natural communication. First, Tartter and Knowlton (1981) found that conversation using DOTS was undisturbed, except during finger spelling, which consists only of changes of handshape and thus allows no guessing. Second, there is an ASL game that plays on the redundancy of handshape: users converse while maintaining a constant handshape. Such games do not exist for the other parameters, suggesting that handshape may be the most redundant parameter.

Besides degrading perception of hand configurations, DOTS displays also eliminate information about other aspects of the body, such as facial expression and body attitude, which are particularly important at the level of syntax and discourse and do usually accompany signs (Baker \& Padden, 1978). Mayberry (1979) has shown that this information is frequently conveyed redundantly by head movement. In DOTS, this may be captured by movement of the nose spot. Nevertheless, one reason that performance may have been uniformly poorer in the DOTS condition is the loss of redundancy due to the substantial reduction in face and body information.

Whenever there is a reduction of information, some loss of perceptibility is to be expected. The greatest weakness of the reduction tested here is in its inability to convey handshape. However, the results of the present study indicate that the distortion in the DOTS condition passes information about many "phonemic" features of the sign signal and thus, when coupled with the normal redundancy present at other levels of the language, may be a suitable system of information reduction for narrow-band transmission.

\section{REFERENCE NOTE}

1. Bellman, K., Poizner, H., \& Bellugi, U. Invariant characteristics of some American Sign Language morphological processes (Salk Institute Working Paper). Unpublished manuscript, Salk Institute, La Jolla, Calif., 1981. 


\section{REFERENCES}

Baker, C., \& Padden, C. Focusing on the nonmanual components of American Sign Language. In P. Siple (Ed.), Understanding language through sign language research. New York: Academic Press, 1978.

Battison, R. M. Phonological deletion in American Sign Language. Sign Language Studies, 1974, 5, 1-14.

Battison, R. M. Lexical borrowing in American Sign Language. Silver Spring, Md: Linstok Press, 1978.

Bellugi, U., \& Siple, P. Remembering with and without words. In F. Bresson (Ed.), Current problems in psycholinguistics. Paris: Centre National de la Recherche Scientifique, 1974.

Grosjenn, F. Sign and word recognition: A first comparison. Sign Language Studies, 1981, 32, 195-220.

Hawes, M. D., \& Danhauer, J. L. Perceptual features of the manual alphabet. American Annals of the Deaf, 1978, 123, 464-474.

Johannson, G. Visual perception of biological motion and a model for its analysis. Perception \& Psychophysics, 1973, 14, 201-211.

Klima, E., \& Bellugi, U. The signs of language. Cambridge: Harvard University Press, 1979.

Kozlowski, L. T., \& Cutring, J. E. Recognizing the sex of a walker from a dynamic point-light display. Perception \& Psychophysics, 1977, 21, 575-580.

Lane, H., Boyes-Braem, P., \& Bellugi, U. Preliminaries to a distinctive feature analysis of handshapes in American Sign Language. Cognitive Psychology, 1976, 8, 263-289.

MAYbenRY, R. Facial expressions and redundancy in American Sign Language. Unpublished doctoral dissertation, McGill University, 1979.

Miller, G. A., \& Nicely, P. E. An analysis of perceptual confusions among some English consonants. Journal of the Acoustical Society of America, 1955, 27, 338-352.

Poiznen, H., Bellugi, U., \& Lutes-Driscoll, V. Perception of American Sign Language in dynamic point-light displays. Journal of Experimental Psychology: Human Perception and Performance, 1981, 7, 430-440.

Poiznen, H., \& Lane, H. Discrimination of location in American Sign Language. In P. Siple (Ed.), Understanding sign language through sign language research. New York: Academic Press, 1978.

Stokoe, W. C., Casterline, D., \& Cronebure, C. A dictionary of American Sign Language on linguistic principles. Washington, D.C: Gallaudet College Press, 1965.

STUno1s, J. Identification and discrimination of handshape in American Sign Language. Perception \& Psychophysics, 1981, 29, 261-276.

TartTen, V. C., \& Knowlton, K. C. Perception of sign language from an array of 27 moving spots. Nature, 1981, 289, 676-678.

Winer, B. J. Statistical principles in experimental design (2nd ed.) New York: McGraw-Hill, 1971.

Wish, M., \& Carroll, J. D. Applications of individual differences scaling to studies of human perception and judgment. Handbook of Perception, 1974, 2, 449-491.

\section{NOTES}

1. Based on the intuitions of one of the authors (with 11 years of signing experience), DEMAND and TIME are more frequent than their counterparts. FISH is more frequent than FLAG, and the others appear to occur equally often. Furthermore, although APPLY is not as appropriate for this frame as PLUGIN, it was selected more often.

2. To test for learning effects, for each condition, performance for each subject for each pair on the first half of the test was compared with performance for that pair on the second half of the test, and the difference was averaged over the nine pairs for each parameter. (On the first half of the test, one member was presented; on the second, the other was presented.) No consistent differences were found, and none of the sums was of sufficient magnitude to be worthy of further analysis.

\section{APPENDIX}

Sentences used to present the minimal pairs are translated/transcribed below. Note that ASL has no written form, and transcription into apparent English words is misleading. Only the signs are transcribed here; facial markers are omitted.

1. THAT PERSON SELF TEND CURIOUS/VOLUNTEER.

2. BIRD/PRINT SUCCESS ARRIVE NOW MORNING.

3. THERE TEACHER CAN'T FIND RED KEY/APPLE, STILL SEARCH \#.

4. THAT STUDENT BETTER/FORGET WORK ON RECENT HOMEWORK.

5. THERE BOY CAN'T STAND BUGS/DEVILS SWARMAROUND HERE ALL-NIGHT.

6. THAT GIRL TRUE UGLY/BORING.

7. THAT MAN HAVE BAD HEADACHE/TOOTHACHE.

8. THERE DEAF PERSON FEEL GUILTY/ALARM AF. TER STEAL.

9. HEY, WHILE-AGO ME SPOT RED BOOK/OPENDOOR THERE.

10. SEARCH \# CAN'T FIND BRIGHT YELLOW SOCKS/ STAR.

11. MOTHER THERE FREEZE/WANT APPLE PIE.

12. THAT BOY NOT-WANT HARD WORK/ROCK ON FOUR-LANE-HIGHWAY.

13. TWO-OF-THEM HATE EACH-OTHER/SCIENCE.

14. CUTE BEAR/MONKEY THERE.

15. THERE WOMAN SERVE/WALK SKILL.

16. MY SISTER INFORM-ME THAT HEAR ARGUMENT/ ALARM OVER THERE.

17. THAT WATER-AROUND SEEM SIMILAR BLUE/ MIRROR SHINY.

18. HEY, PLEASE HOIST-UP FLAG/FISH B>-CLASSIFIER UP/B -CLASSIFIER-UP.

19. ONE CAT CARELESS WALK [WRONG] PUSH POUROUT SPREAD SPAGHETTI/THREAD CHAOS.

20. IMAGINE APPLY/PLUG-IN, WILL SUCCESSFUL.

21. MY GRANDMOTHER FALL-IN-LOVE-WITH PIANO/ TYPEWRITER.

22. AMPUTATE-ARM MAN SUFFER/PATIENT PAIN.

23. THERE BOY ADORE DRIVING/CARS.

24. THERE GIRL NEED PAINT/SOAP TO ERADICATE DIRTY SPOT ON TABLE.

25. KNOW WHAT? KNOW WHAT? FEEL + THAT WONDERFUL WORKER JOIN/QUIT HERE LAST WEEK.

26. THAT TOWN HAVE MANY PAPER/SCHOOL MANYLUMPY-THINGS.

27. THAT PIRATE LONG-TIME-AGO DIG/DEMAND ISLAND FOR MONEY.

28. HEY, WARN + , THAT MAN THERE SELF HOT TEMPER IRISH/PRINCIPAL.

29. PREACHER THERE CAN'T STOP/APPROVE SMOKING IN CHURCH.

30. PLEASE BRING WATER/VINEGAR FOR SOUP.

31. RAIN/DYE FINISH, ME GONE GATHER-UP WET CLOTHES.

32. FINE, HAVE PLENTY TIME/POTATOES COOK.

33. THERE BOY DON'T-WANT/FINISH SUPPER.

34. THERE, MAN BET/AGREE THERE ${ }_{2}$ HORSE WILL WIN.

35. TWO-OF-THEM LOVE DANCING/PAINTING.

36. JAPAN THERE WHILE-AGO ME SEE MANY ALMOST NAKED MEN WORSHIP/WRESTLE.

(Manuscript received December 30, 1981; revision accepted for publication July 15,1982 .) 